\title{
Factors influencing the seed source and sink functions of a floodplain nature reserve in the Netherlands
}

\author{
Hester Soomers, Judith M. Sarneel, Wouter Patberg, Steven K. Verbeek, Pita A. Verweij, \\ Martin J. Wassen \& Rudy van Diggelen
}

\section{Keywords}

Diaspores; Floodplain restoration; Hydrochory; Inundation; Plant seeds; River; Seed dispersal; Spatial variables; Species traits.

Nomenclature

Van der Meijden (2005)

Received 17 June 2010

Accepted 6 January 2011

Co-ordinating Editor: David Ward

Soomers, H. (corresponding author, H.Soomers@geo.uu.nl) \& Wassen, M.J. (m.wassen@geo.uu.nl): Department of Environmental Sciences, Faculty of Geosciences, Utrecht University, P.O. Box 80115, NL-3508 TC Utrecht, The Netherlands Sarneel, J.M. (j.sarneel@nioo.knaw.nl): Ecology and Biodiversity, Faculty of Science, P.O. Box 80084, NL-3508 TB Utrecht, The Netherlands Patberg, W. (w.patberg@rug.nl): Laboratory of Plant Physiology, University of Groningen, Kerklaan 30, NL-9751 NN Haren, The Netherlands

Verbeek, S.K. (s.verbeek@noorderzijlvest.nl): Water Board 'Noorderzijlvest', P.O. Box 18, NL9700 AA Groningen, The Netherlands

Verweij, P.A. (p.a.verweij@uu.nl): Group Science, Technology and Society, Faculty of Science, Utrecht University, P.O. box 80083 NL3508 TB Utrecht, The Netherlands

Van Diggelen, $\mathbf{R}$.

(ruurd.van.diggelen@ua.ac.be): Ecosystem Management Research Group, University of Antwerp, Universiteitsplein 1, B-2610 Wilrijk, Belgium and Faculty of Spatial Sciences, University of Groningen. P.O. Box 800, NL-9700 AV Groningen, The Netherlands.

\begin{abstract}
Question: How do species traits and abiotic factors influence the extent of hydrochorous dispersal into and out of a small floodplain area along a freeflowing river in The Netherlands?
\end{abstract}

Location: The Kappersbult nature reserve $\left(53^{\circ} 07^{\prime} 28^{\prime \prime} \mathrm{N}, 6^{\circ} 37^{\prime} 14^{\prime \prime} \mathrm{E}\right)$, which is a floodplain along the Dutch River Drentsche Aa.

Methods: Seeds transported by the river were collected in fine mesh nets for 24 consecutive hours once or twice a week for 1 year, upstream and downstream of the studied floodplain. Data on the captured seeds were related to species traits and abiotic factors and species composition in the floodplain.

Results: The floodplain functioned both as a seed source and sink. High levels of river water seemed to promote seed transport to or from the floodplain. Seeds of riverbank species occurred significantly more often in the river water than expected. Net source species had significantly higher seed production, taller stature and higher seed buoyancy, but lower site elevation than net sink species. Seed weight was significantly higher for sink species than for other species.

Conclusion: Our study found that inundation, and therefore more natural river water management, is a prerequisite for seed transport to and from a floodplain. The restoration of target floodplain vegetation may be successful for common species that produce many seeds and grow in proximity to the river. Consequently, it is expected that the probability of restoring vegetation types that occur further from the river, such as wet grasslands, by hydrochorous dispersal is low.

\section{Introduction}

European river basins have been used intensively for centuries. The canalization and regulation of rivers and the reclamation and eutrophication of floodplains have resulted in a decline in water quality and biodiversity (Nienhuis \& Leuven 2001; Jensen et al. 2006). Recently, the focus with respect to river management has changed to a more natural approach, in anticipation of the EU Water Framework Directive (Nienhuis et al. 2002). In addition, the implementation of the Dutch policy directive 'Room for the River' (Baan \& Klijn 2004), which is aimed at mitigating the effects of peak discharges of major rivers in the future, requires a shift in river management policy. The forthcoming implementation of these legislative measures requires profound knowledge of the 
functioning of ecosystems in riverine habitats and provides the opportunity to restore floodplain habitats.

Although attempts to restore habitats are often successful, characteristic target species are not necessarily reestablished (Grootjans et al. 2002; Jensen et al. 2006). A major constraint in the re-establishment of target plant communities is the limited availability of propagules (Ehrlen \& Eriksson 2000; Bischoff 2002; Boedeltje et al. 2003; Ehrlen et al. 2006; Jansson et al. 2007). For instance, Ozinga et al. (2005) concluded from their study that poorer dispersers were under-represented in suitable habitat patches, in contrast to plants with a high capacity for long-distance dispersal.

For riparian plant seeds, surface water is an important dispersal vector (e.g. Schneider \& Sharitz 1988; Nilsson et al. 1991; Goodson et al. 2003; Boedeltje et al. 2004; Gurnell et al. 2006; Soomers et al. 2010), and hydrochory (i.e. water dispersal) is especially important for the restoration of plant communities in river valleys (Rosenthal 2006). Furthermore, Van den Broek et al. (2005) found a positive correlation between the flooding probability of plant communities and the average seed buoyancy in species from these communities. Consequently, the dispersal range of riparian plant species is much greater than when dispersal takes place exclusively by anemochory (i.e. wind dispersal) (Boedeltje et al. 2003). The discharge dynamics of river water, and more specifically, flood pulses (Junk et al. 1989) are considered to be important factors that influence hydrochory (Moggridge et al. 2009). For riverine plant communities, the importance of flood pulses has been stressed in Middleton (1999), Tockner et al. (2000) and Boedeltje et al. (2004). Similarly, Jansson et al. (2005) found that flooding had a positive effect on plant biodiversity along the river.

When focusing on hydrochory in floodplains, two different processes must be distinguished; (1) seed inflow to and deposition in a floodplain (seed sink function), and (2) outflow from a floodplain of seeds produced there (seed source function). Both processes are important for the maintenance of populations of riparian plant species that occur in a metapopulation along a river. In this paper, seed source and seed sink functions only refer to seedrelated dispersal processes, not to source or sink populations as described within the metapopulation theory (Hanski 1999).

Only a few of the numerous studies that have investigated hydrochory relate species traits to the presence and abundance of species in seed samples that have been captured in a river (Boedeltje et al. 2003; Vogt et al. 2006; Gurnell et al. 2008). Moreover, these studies did not take into account the spatial location of possible source plants, nor did they analyse the relation between river water levels and the transport of seeds. The study reported herein had as its aim investigation of the influence of species traits and abiotic factors on the extent of hydrochorous dispersal into and out of a floodplain area along a free-flowing river in The Netherlands.

In contrast to other studies that focus either on diaspore deposition at river margins or floodplains (e.g. Merritt $\delta$ Wohl 2006; Vogt et al. 2007) or on the quantification of the flow of propagules through a river (e.g. Boedeltje et al. 2003, 2004), our experimental approach and the spatial configuration of the floodplain allowed us to distinguish between seed inflow and outflow and to evaluate separately the species traits and abiotic factors that influence each process.

The main research questions addressed in this study are: (1) does the considered floodplain function as a net seed source or seed sink, and (2) which plant traits and growing location characteristics are related to these two different processes? We examined the species traits seed buoyancy, seed weight, seed-shedding season, plant height and seed production in the floodplain, and the abiotic factors river water level, soil elevation and distance to the river of source plant locations. Our study focuses on herbaceous species only.

In the study area, except for riparian vegetation, other types of floodplain vegetation are absent upstream of the floodplain under consideration. Therefore, we hypothesize that the floodplain functions as a net source of seeds towards downstream areas for plants that inhabit the studied floodplain.

\section{Methods}

\section{Site description}

The 27 ha Kappersbult nature reserve $\left(53^{\circ} 07^{\prime} 28^{\prime \prime} \mathrm{N}\right.$, $6^{\circ} 37^{\prime} 14^{\prime \prime} \mathrm{E}$ ) is a single separate floodplain area along the small Dutch river Drentsche Aa (see Fig. 1). Upstream of the study site, the river is embanked, without the presence of floodplains. The river banks consist of sandy vegetated levees. Vegetation in the floodplain ranges from highly productive types [tall sedges (Caricion gracilis), reed canary grass marshes (Phalaris arundinacea community) and reed manna grass marshes (Glyceria maxima community)] close to the river, through small sedge vegetation (Caricion nigrae), to low productivity litter meadow (Junco molinion) and grassland (Calthion palustris) furthest from the river (Bakker et al. 1987; Klimkowska et al. 2009). The average discharge of the river is $1.95 \pm 1.85 \mathrm{~m}^{3} \mathrm{~s}^{-1}( \pm \mathrm{SD}$; 1998-1999) and the water level ranges from $0.51 \mathrm{~m}$ to $1.47 \mathrm{~m}$ (average $0.65 \pm 0.088 \mathrm{~m}$ ) above mean sea level (a.s.l.) (1998). River water levels do not fluctuate strongly as a consequence of downstream water regulation. 


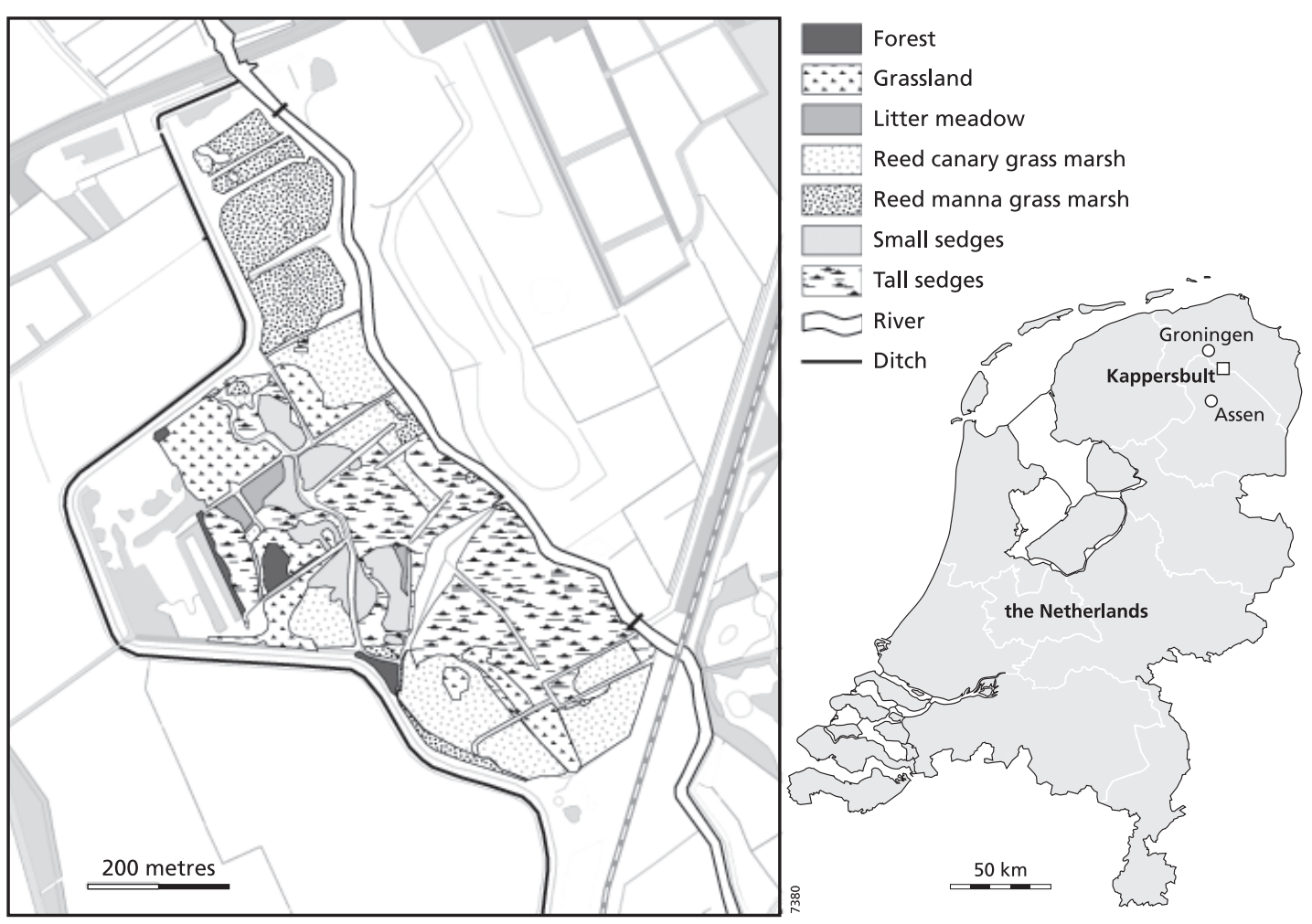

Fig. 1. The location of the research site in The Netherlands, the distribution of vegetation types and location of the nets within the research site.

\section{General approach}

To quantify the number of seeds transported by the river, seeds were collected in fine mesh nets for 24 consecutive hours once or twice a week over 1 year, upstream and downstream of the studied floodplain nature reserve. These numbers and the species caught were compared with the estimated number of seeds produced in the floodplain, and with the species composition of the floodplain. The sampling design enabled us to calculate the net seed inflow or outflow. We define the net seed inflow, or seed sink function, of the floodplain as the net inflow of seeds from the river into the floodplain (number of seeds captured upstream $>$ number of seeds captured downstream). Similarly, we define the net seed outflow, or source function, of the floodplain as the net outflow of seeds from the floodplain into the river (number of seeds captured downstream $>$ number of seeds captured upstream). However, it should be noted that some seeds could also remain in the river channel between the upstream and downstream nets (Gurnell et al. 2007).

Species traits, such as seed weight and seed buoyancy, and spatial variables, such as the average distance of plant sites to the river, were compared between species for which the floodplain functioned as a (net) seed source (hereafter referred to as '(net) source species') and other species, and also between species for which the floodplain functioned as a (net) sink and other species. Furthermore, the river water level was related to the net outflow of viable seeds that were captured in every 2 -wk period.

\section{Seeds transported by the river}

\section{Trapping of seeds transported by the river}

Fine mesh nets (mesh size: $150 \times 150 \mu \mathrm{m}$ ) fixed to a $53 \times 50 \mathrm{~cm}(53 \times 25 \mathrm{~cm}$ subsurface $)$ wooden frame with attached wooden floats were used to collect waterborne seeds. Note that the nets only sampled the water column near the water surface. Three nets were placed upstream (south) and three downstream (north) of the nature reserve, equidistant from each other and from the riverbanks (see Fig. 1). At the northern location, the river was $18.8-\mathrm{m}$ wide, and at the southern location, $14.4 \mathrm{~m}$. The two seed capture locations were 1282-m apart. Between June and November 1998, seeds were trapped twice a week by putting nets in the river on Monday and Thursday and taking them out $24 \mathrm{~h}$ later. Between December and May 1999, we sampled once a week because we expected lower seed numbers in winter. During the latter period, we sampled on Monday, except for three instances, when we sampled on Tuesday. 


\section{Identification of trapped seeds}

The collected nets were rinsed and the captured seeds were stratified at $4{ }^{\circ} \mathrm{C}$ for at least 1 month under moist conditions. After stratification, samples were sown on wet sterile soil that was covered with a thin layer of sterile sand and placed in a greenhouse at temperatures of $25^{\circ} \mathrm{C}$ during the day and $15^{\circ} \mathrm{C}$ at night. A regime of 12 -h light and 12 -h darkness was maintained. Seeds that germinated were removed after they had been identified. This procedure was continued until no new seedlings emerged for at least 4 weeks. Not all seedlings could be identified to species level.

\section{Calculation of total annual number of seeds transported by the river}

The total number of captured viable seeds was transformed into annual number of viable seeds per species transported across the entire river width at the two locations, using equation 1 .

$S_{t o t, s, a}=S_{c, s, a}\left(t_{j} / t_{c}\right)\left(w_{r, a} / w_{n}\right)$

In equation $1, S_{\text {tot, s,a }}$ represents the annual number of seeds for species $s$ at location $a$. $S_{c, s, a}$ represents the total number of captured $(c)$ seeds for species $s$ at location $a, t_{j}$ the number of minutes in a year $(525600), t_{c}$ the number of minutes for which these seeds were captured, $w_{r, a}$ the width of the river at location $a$ and $w_{n}$ the total width of the three nets $(1.59 \mathrm{~m})$.

\section{Species traits and abiotic explanatory variables}

Timing of seed-shedding and river water level

To relate seed transport by the river to the seed-shedding period and river water level, for all species in the river and the floodplain, seed-shedding periods were extracted from a database (Kleyer et al. 2008). Furthermore, The Hunze and Aa Regional Water Board provided data on river water levels, measured downstream of the Kappersbult (Fig. 2).

\section{Species traits and spatial variables}

To analyse potential differences in species traits and spatial variables between (net) source and (net) sink species, data on seed weight (Flynn et al. 2006), minimum plant height (van der Meijden 2005) and seed buoyancy (Boedeltje et al. 2003; van den Broek et al. 2005) were derived from the literature. We used the buoyancy data in Boedeltje et al. (2003). Buoyancy data for additional species were derived from Van den Broek et al. (2005) by standardizing these values to the data set of Boedeltje et al. (2003) using a regression analysis.
To gain insight in the species composition and seed production in the floodplain, vegetation relevés $(0.9 \times$ $0.9 \mathrm{~m}$ ) were taken in 10 randomly selected representative subplots in each community. For a detailed description of the methodology used to sample the vegetation and to estimate the seed production, see Klimkowska et al. (2009). We estimated the number of seeds per species in each plot and multiplied the estimated number of seeds per vegetation type with the area of each vegetation type to estimate the number of seeds per species that were produced in the floodplain (Klimkowska et al. 2009). No vegetation relevés were undertaken in the forested patches, and therefore, trees and woody species were excluded from this analysis.

Using GIS maps with the spatial location of vegetation types and the location of the river, and the data on estimated numbers of seeds produced per species per vegetation type in the floodplain, the weighted average and weighted average minimum distance from the growing location to the river were calculated for each plant species present in the floodplain. Similarly, the weighted average, weighted average minimum and weighted average maximum soil elevation of the growing location were calculated for each species using an elevation raster map (van Heerd et al. 2000).

The average water level of the Drentsche Aa River was $0.65 \mathrm{~m}$ a.s.l. To investigate the effect of inundation on the number of waterborne seeds, the estimated number of seeds produced at sites that would be inundated when the water level rises to $0.8 \mathrm{~m}$ was calculated using an elevation raster map and the gathered information on seed production per species per vegetation type. We chose a height of $0.8 \mathrm{~m}$ a.s.l. as the river water level at which overbank flooding starts to occur. Our choice was based on the fact that about $10 \%$ of the riverbank is lower than this height, assuming significant overbank flooding at this water level. Furthermore, approximately $25 \%$ of the floodplain area is below this level.

\section{Data analysis}

The floodplain as a net seed source or sink?

We tested all data for normality and homogeneity of variance. If assumptions of parametric statistical tests were violated, we used a non-parametric test.

Total numbers and species of seeds that were captured upstream and downstream were compared with species growing in the floodplain. For species that were found in the floodplain and exclusively in the downstream nets (as seeds), the percentage of seeds produced in the floodplain in 1 year that reaches the river water was assessed using the calculated number of produced seeds in the floodplain and the calculated total number of seeds transported 


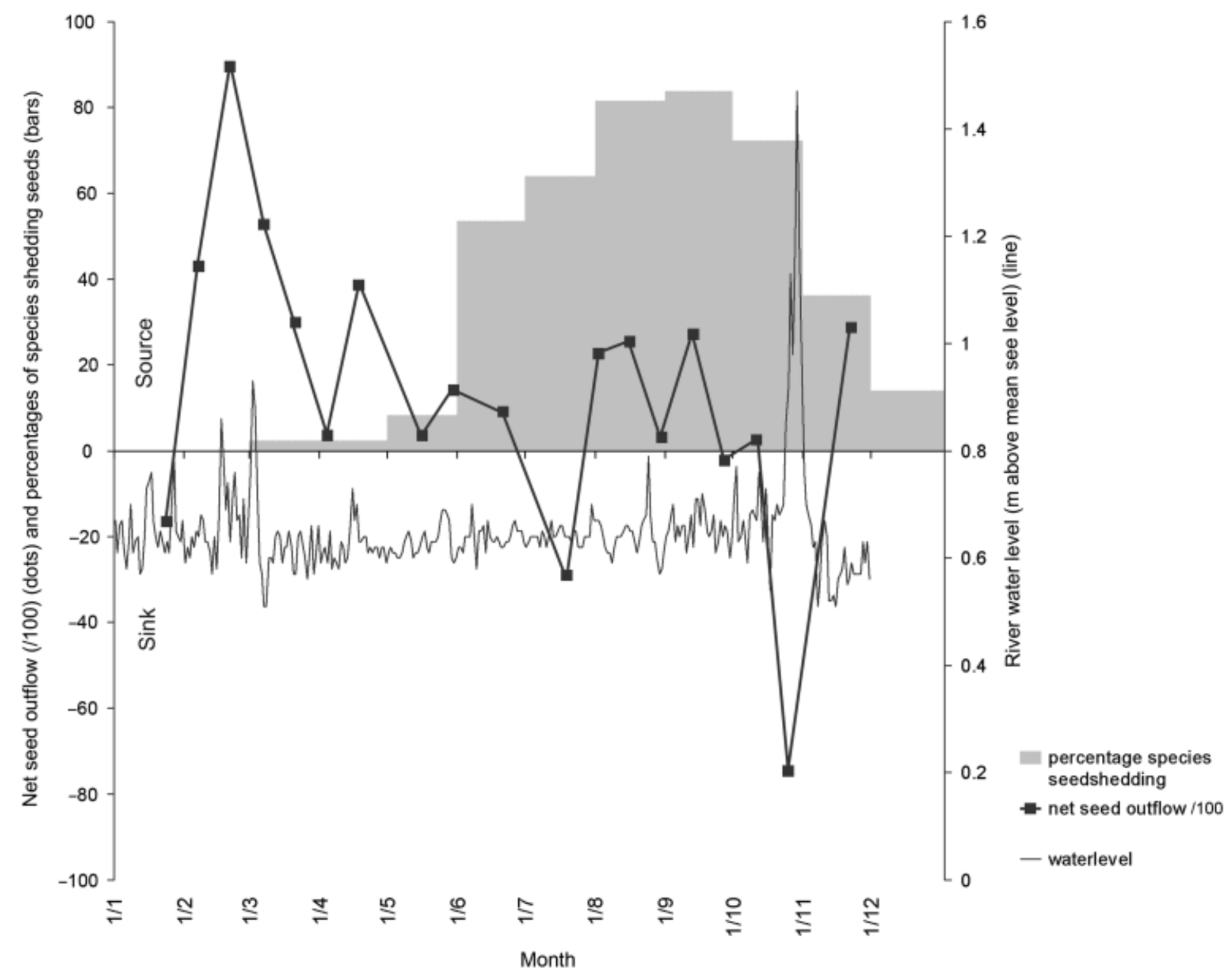

Fig. 2. River water level in 1998 (June-December) and 1999 (January-May) of the River Drentsche Aa (line, right y-axis), percentage of species that release seeds in the considered months (bars, left $y$-axis) and net seed outflow divided by 100 (seeds downstream minus seeds upstream) (black dots, left $y$-axis; each dot represents the total number of seed outflow in a 2-week period, river-wide). Water level data for December were not available.

through the river downstream of the floodplain. The number of seeds trapped upstream was related to the number of seeds trapped downstream, for each species, using a Spearman correlation test.

\section{Timing of seed-shedding and river water level}

To test the hypothesis that more seeds will reach the river water in the seed-shedding season of the considered species, for both the upstream and downstream locations, the average number of viable seeds per month found in the nets in the seed-shedding period of a considered species was compared with the average number of seeds per month in the period in which no seeds are shed by this species (Wilcoxon test).

To relate the river water level to number of seeds trapped upstream or downstream and to net seed outflow, 2-week averages of river water level and 2-week total number of captured viable seeds were used. For these analyses, the number of captured viable seeds for the different species was summed in order to derive the total number of captured viable seeds. In contrast to the species-specific data set, data for this analysis were normally distributed. To investigate the effect of river water level on the net inflow/outflow of viable seeds, a Pearson correlation test was used.

\section{Species traits and spatial variables}

To investigate the effect of species traits and spatial characteristics of their growing location on the net seed inflow or outflow for herbaceous species, four issues were addressed, each with a corresponding analysis. Different selections of species (excluding the woody species Alnus spp, Betula pubescens, Crataegus monogyna, Salix alba and Salix cinerea) were made for the purpose of each analysis, 
Table 1. Figures on calculated annual number of seeds and number of species captured in upstream and downstream nets and growing in the Kappersbult. *some species also occur in the Kappersbult.

\begin{tabular}{|c|c|c|c|c|}
\hline & $\begin{array}{l}\text { Computed annual } \\
\text { number of seeds }\end{array}$ & $\begin{array}{l}\text { Number of } \\
\text { identified species }\end{array}$ & $\begin{array}{l}\text { Number of identified } \\
\text { species also growing } \\
\text { in the Kappersbult }\end{array}$ & $\begin{array}{l}\text { Number of identified } \\
\text { species exclusively at } \\
\text { the location described } \\
\text { in the first column }\end{array}$ \\
\hline Seeds captured in upstream nets & 111429 & 63 & 28 & $18^{*}$ \\
\hline Seeds captured in downstream nets & 103038 & 58 & 25 & $13^{*}$ \\
\hline Total seeds captured in nets & 214467 & 76 & & \\
\hline Number of species of seed found in both nets & & 45 & 22 & \\
\hline $\begin{array}{l}\text { Species growing in/seeds produced in } \\
\text { Kappersbult }\end{array}$ & $25117 \cdot 10^{6}$ & 63 & & 32 \\
\hline
\end{tabular}

according to the location(s) of seed capture and the presence or absence of the plant species in the floodplain (see Table 2).

We investigated (1) which species traits and spatial variables determine whether a species that is growing in a floodplain enters the river water; (2a) which species traits and spatial variables determine whether a species that is growing in the floodplain acts as a net seed source species, (2b) which species traits and spatial variables determine whether a species that is growing in the floodplain and interacting with the river acts as a net seed source or sink species; and (3) which species traits determine the inflow of seeds to the floodplain from the river.

In each of the analyses, the differences in species traits and spatial variables were tested between the two groups ((net) sink and (net) source species) mentioned in Table 2, using a Mann-Whitney $U$-test.

1: Exclusive source analysis

Considering analysis 1 , a selection of the total data set, including only species that occur in the Kappersbult and were not found in the upstream nets was made. Within this selection, the species traits and spatial variables were compared between species not found in the downstream nets (group a) and species that were found in the downstream nets (group b). It is assumed that only species from group $b$ were able to enter the river water.

\section{$2 a / 2 b$ : Net source/sink analysis}

The selection for analysis 2 a comprised all species that were present in the floodplain, within which species that were more abundant in the downstream nets than upstream (net source species, group a) were compared with the species for which this did not hold (group b). In analysis $2 \mathrm{~b}$, the same selection and groups as in analysis 2a was used, except for the exclusion of species that were not found in any net in this analysis.

3: Exclusive sink analysis

Analysis 3 considered a selection of species that did occur in the upstream nets, but were not found in the floodplain. In this analysis, variables for species not found downstream ('exclusive sink species', group a) were compared with those for species found in both nets (group b). Because the species selected in this analysis did not grow in the floodplain, spatial variables were omitted for this analysis.

\section{Results}

The floodplain as a net seed source or sink?

Total number of seeds and species that were captured upstream and downstream and identified in the floodplain are given in Table 1 . Table S1 in the Appendix lists the identified species that were found either in the vegetation of the Kappersbult or in at least one of the nets. The computed annual number of viable seeds floating along the total width of the river was similar at the downstream and upstream locations (Table 1). From viable seeds caught in the river during the year-round experiment, 76 different species could be identified to species level. As seen in Tables 1 and S1, 45 species were found in both nets, 18 only upstream and 13 only downstream. Of the 13 species that were found exclusively in the downstream nets, three (Glyceria maxima, Carex nigra and Typha latifolia) occurred in the Kappersbult vegetation (see Table S1). For Carex nigra, $0.00264 \%$ and for Glyceria maxima $0.000022 \%$ of the seeds produced in the Kappersbult reached the river water downstream of the area and remained viable. No estimation of seed production was available for Typha latifolia. The most abundant herbaceous species in the upstream nets were Juncus bufonius, Poa trivialis and Juncus effusus, while Epilobium hirsutum and Lycopus europaeus were the most abundant species in the downstream nets (see Appendix). A total of 55.3\% of the captured species were found more often in the upstream than in the downstream nets. There was a significant correlation between the number of seeds per species captured in the upstream location and captured 
Table 2. Comparison of species traits and spatial variables between two groups ( $a$ and $b$ ) of species, for four selections of species found as seeds in the river and/or as plants in the floodplain. Locations considered in the selection: $F=$ Floodplain, $U=$ Upstream nets, $D=$ downstream nets. Bullets refer to criteria for selection of species: $\bullet=$ All species found at this location are included in the selection, $o=$ All species absent at this location are included in the selection. *Species not found in the river at all were excluded from the selection. If two criteria are used, both the first and the second apply to the selection. $P=$ significance value. $\dagger$ Spatial variables were omitted in analysis 3 because these species were absent in the floodplain.

\begin{tabular}{|c|c|c|c|c|c|c|c|}
\hline \multirow[t]{2}{*}{ Name of analysis } & \multicolumn{3}{|c|}{ Selection } & \multirow[t]{2}{*}{ Group a } & \multirow[t]{2}{*}{ Group b } & \multicolumn{2}{|c|}{ Mann-Whitney U-test, comparing group a with group b } \\
\hline & $F$ & U & $\mathrm{D}$ & & & Variable & Result \\
\hline 1: Exclusive source & $\bullet$ & $\circ$ & & $\begin{array}{l}\text { Species found in } \\
\text { downstream nets } \\
\text { (exclusive source species) }\end{array}$ & $\begin{array}{l}\text { Species not found in } \\
\text { downstream nets }\end{array}$ & $\begin{array}{l}\text { Seed production at } \\
\text { locations lower than } \\
0.8 \mathrm{~m}\end{array}$ & $a>b, P=0.011$ \\
\hline 2a: Net source/sink & $\bullet$ & & & $\begin{array}{l}\text { Species found } \\
\text { downstream more often } \\
\text { than upstream (net source } \\
\text { species) }\end{array}$ & $\begin{array}{l}\text { Species not found more } \\
\text { often downstream }\end{array}$ & $\begin{array}{l}\text { Seed production: } \\
\text { Seed production at } \\
\text { locations lower than } \\
0.8 \mathrm{~m} \\
\text { Minimum plant height }\end{array}$ & $\begin{array}{l}a>b, P=0.015 \\
a>b, P=0.003\end{array}$ \\
\hline 2b: Net source/sink & • & * & * & $\begin{array}{l}\text { Species found } \\
\text { downstream more often } \\
\text { than upstream (net source } \\
\text { species) }\end{array}$ & $\begin{array}{l}\text { Species found more } \\
\text { upstream than } \\
\text { downstream (net sink } \\
\text { species) }\end{array}$ & $\begin{array}{l}\text { Minimum soil elevation } \\
\text { Buoyancy } \\
\text { Minimum plant height }\end{array}$ & $\begin{array}{l}a<b, P=0.038 \\
a>b, P=0.01 \\
a>b, P=0.003\end{array}$ \\
\hline 3: Exclusive sink $\dagger$ & $\circ$ & $\bullet$ & & $\begin{array}{l}\text { Species not found in } \\
\text { downstream nets } \\
\text { (exclusive sink species) }\end{array}$ & $\begin{array}{l}\text { Species found in both nets } \\
\text { (hydrochoric species from } \\
\text { upstream) }\end{array}$ & Seed weight & $a>b, P=0.011$ \\
\hline
\end{tabular}

downstream (Spearman correlation coefficient $=0.541$, $P<0.001)$. Nevertheless, many species exhibited distinct net inflow or outflow rates (see Table S1).

\section{Timing of seed-shedding and river water level}

Figure 2 shows that during the seed-shedding season, most of the time the river water levels were too low to allow overbank flooding of the floodplain; except for one flooding event that began at the end of October and lasted until the beginning of November.

There was no significant difference between the average monthly number of seeds found in the nets during the seed-shedding season of each species and the number of seeds outside the seed fall season, for both the upstream and the downstream nets (Wilcoxon, $P=0.238$ and 0.924, respectively).

The 2-week average river water level did not correlate significantly with either the 2-week number of seeds trapped upstream or downstream (Pearson, $P=0.558$ and $P=0.925$ respectively), or the net seed outflow $(P=0.391)$. Similarly, the 2 -week maximum river water level was not correlated significantly with the number of seeds trapped upstream, downstream or net seed outflow (Pearson, $P=0.950, P=0.997$ and $P=0.933$, respectively). However, Fig. 2 illustrates that the third peak in river water level, which began at the end of October and lasted until the beginning of November (i.e. towards the end of the seed shedding season), coincides with a clear net inflow of seeds to the floodplain, whereas higher river water levels in February and March coincide with a net outflow of seeds. For lower water levels, the net seed outflow was closer to zero.

\section{Species traits and spatial variables}

Exclusive source analysis

Seed production at lower sites of the floodplain $(<0.8 \mathrm{~m}$ a.s.l.) was significantly higher for exclusive source species (see Table 2, analysis 1) than for species for which no viable seeds entered the river water from the floodplain (Mann-Whitney $U, P=0.011, N=27$, Table 2). A trend to higher seed production in the floodplain for absolute source species compared to non-hydrochorous species was found (Mann-Whitney $U, P=0.051, N=27$, Table 2). Other variables did not differ significantly among the two groups.

\section{Net source/sink analyses}

Considering all species growing in the floodplain separately, a Mann-Whitney $U$-test yielded a significantly higher estimated number of seeds produced in the nature reserve for net source species (see Table 2, analysis 2a) 
than for net sink and non-hydrochorous species $(P=0.015, N=49)$. Furthermore, the minimum plant height and number of seeds produced at lower sites were significantly higher for net source species than for net sink and non-hydrochorous species $(P=0.013, N=63$ and $P=0.003, N=49$, respectively). There was a trend towards a smaller minimum distance of the species' location to the river and towards a lower minimum soil elevation for net source species $(P=0.052, N=49$ and $P=0.059, N=49$, respectively). This was confirmed by a Chi-square test, which revealed that species that are found at the riverbank of the floodplain had a positive net seed outflow significantly more often, and species that are found in the floodplain and not at the riverbank significantly less often than expected (Chi-square, $P=0.012, N=63$ ). A trend to a higher buoyancy for net source species was found (MannWhitney $U, P=0.093, N=47)$. Other variables did not differ significantly among the two groups.

For analysis $2 b$, species that were found in the Kappersbult, but not in one of the nets, were excluded from the selection (see Table 2, analysis $2 \mathrm{~b}$ ). For this selection, minimum plant height and seed buoyancy were significantly higher for net source than for net sink species (Mann-Whitney $U, P=0.003, N=31$ and $P=0.01, N=26$, respectively). Minimum soil elevation was significantly lower for net source species and there was a trend towards a smaller minimum distance to the river for net source species $(P=0.038, N=24$ and $P=0.081, N=24$, respectively). Other variables did not differ significantly among the two groups.

\section{Exclusive sink analysis}

For species not growing in the floodplain, but found in the upstream nets, seed weight was significantly higher for exclusive sink species (see Table 2, analysis 3) than for species found in both nets (Mann-Whitney $U, P=0.009$, $N=33$ ). A trend towards lower buoyancy for absolute sink species was found (Mann-Whitney $U, P=0.098, N=17$ ). Minimum plant height did not differ significantly among the two groups.

\section{Discussion}

\section{Net seed source or sink?}

Our study considers one relatively small separate floodplain area, situated along a part of an embanked river. Although this setting has limitations for the general applicability of our results, it enables us to distinguish the specific contribution of the floodplain as a seed source for downstream areas as well as the specific function of the floodplain in capturing seeds carried by the river. The results do not support the initial hypothesis that the
Kappersbult floodplain functions mainly as a seed source. The floodplain appears to function as either a seed source or as a sink, depending on the species and conditions. However, for at least half of the species in the data set $(55 \%)$, the Kappersbult functions as a net seed sink; the evidence for this claim being that the total number of viable seeds for these species was lower in the river downstream of the floodplain than upstream. Furthermore, the number of species found in the upstream nets was higher than in the downstream nets.

The herb species that were most abundant in the downstream nets also occurred in the floodplain vegetation and the upstream nets. Species that were abundant in the nets are common species that are not confined to floodplains, but can also grow on river levees. However, for species that occur in small sedge and wet grassland (Litter meadow and Grassland) vegetation in the Kappersbult, exchange of seeds between floodplain and river seems much less common. Only the small sedge Carex nigra, which produced many seeds in the floodplain, was found in the downstream nets, whereas the small sedges C. curta, C. panicea and C. aquatilis, and the wet grassland species Silene flos-cuculi and Caltha palustris occurred in neither the downstream nor the upstream nets. These results indicate that, although flooding of the Small sedge, Litter meadow and Grassland vegetation is possible, the effect of hydrochory on the vegetation composition of floodplain species that do not grow at riverbanks is very limited. This is in agreement with the results of Bissels et al. (2004), who conclude that restoring more natural flooding conditions did not result in the recovery of species richness of alluvial grasslands in Germany. For seeds of more distant floodplain species, the coupling of anemochory (primary dispersal) and hydrochory (secondary dispersal) could result in long-distance dispersal. However, if this strategy were very successful in dispersing seeds via river water, we would expect to find a higher number of seeds of these species in the downstream nets than we did.

Thirteen species were found exclusively in the downstream net, but of these only three occurred in the floodplain. This may indicate that the methods used to capture seeds were not as efficient as they might have been, with the result that a number of species were not collected in the upstream nets. Alternatively, these species (a) may be present in the Kappersbult but may have been overlooked by us while mapping species, or (b) may be present along the riverbank opposite the floodplain in the stretch between the upstream and downstream net.

These various possibilities illustrate the general uncertainties related to studies of seed dispersal. Seed dispersal is a stochastic process and, whatever methods are used for 
capturing seeds, in most cases only a small proportion of the seeds can be captured. This holds especially for wind dispersal studies, but also applies to our case, in which we could not sample the entire width of the river continuously for a year. Hydraulic variation within the river could prevent uniform distribution of seeds across the channel. This could mean that the annual calculations of seed numbers across the entire river width could be an overor under-estimation, depending on the exact manifestation of this variation. Moreover, extrapolating a process that is stochastic over time also brings the risk that either rare species are not found, or that rare events/species that are coincidentally sampled are given an unrealistically high weight as a result of extrapolation. Furthermore, the nets with the small mesh size (used to make sure that even very small seeds were captured) can be blocked by drifting material, as a result of which the effective trapping period may have been shorter than $24 \mathrm{~h}$ (Boedeltje et al. 2003). Therefore, we note that caution must be taken when drawing conclusions from seed capture studies such as ours, because of sampling constraints and stochasticity. In particular, caution should be observed when drawing conclusions from the calculated annual seed numbers; these should be seen as rough estimates rather than precise figures. However, our sampling design was dense compared to other studies; we sampled about $10 \%$ of the river width, frequently, for 1 year, while many other studies only considered samples taken over a much shorter period of time, less frequently (Goodson et al. 2003; Moggridge et al. 2009; Moggridge \& Gurnell 2010) or even only after one flooding event (Cellot et al. 1998; Andersson et al. 2000; Vogt et al. 2006, 2007).

In summary, we conclude that floodplains can function both as seed source and sink, but that source-sink dynamics with accompanying genetic exchange between sub-populations might only play a visible role for common species growing on riverbanks or dykes.

\section{Timing of seed-shedding and river water level}

In our study, the high water level peak in autumn, shortly after the seed fall season, was related to net seed deposition in the floodplain. However, high water levels in winter (February-March) corresponded to a clear net seed outflow, rather than seed deposition. In relation to the former effect, other studies report a considerable amount of overall seed deposition after flooding (Vogt et al. 2004, 2006). We found no direct evidence in the literature for the latter effect (e.g. source effect). However, Boedeltje et al. (2004) found indirect evidence in the form of a positive relation between mean number of species and diaspores captured in a channel and high water discharge levels. Further, the river flow regime according to time of year has been reported to influence hydrochory by, for example, Boedeltje et al. (2004), Gurnell et al. (2006) and Moggridge \& Gurnell (2010).

We suggest that seed transport to or from a floodplain is initiated by flooding, but that the main direction of the transport (net source or net sink) depends on the time of the year. In herbaceous wetlands, vegetation roughness is probably greater in autumn, just after the seed shedding season, than in late winter, when most plants have decayed. Therefore, we hypothesize that, during late winter, seeds lying on the soil surface might reach the river more easily after inundation. In autumn, most seeds are captured in the vegetation, whether they were deposited by the river or originated from the vegetation. The importance of vegetation roughness in relation to hydrochory is also mentioned in Pollux et al. (2009).

Our results show that flooding events seem to promote both the deposition of seeds in floodplains and the outflow of seeds from the floodplain. Hence, inundation is expected to promote the ability to colonize, and therefore the viability of wetland plant species, by connecting otherwise fragmented wetland patches. This implies that the regulation of river water levels, which results in constant water level without flooding events, can diminish the effectiveness of a river as a dispersal vector. This is supported by the flood pulse concept (Junk et al. 1989; Middleton 1999), which states that the inundation of floodplains by a free-flowing river is a prerequisite for the restoration of riverine biodiversity. We note that the river in our study area was a low-energy river. In contrast, in high-energy river systems, seeds might be mobilized from the riverbed within a river reach (Gurnell et al. 2008). Furthermore, in rivers with higher energy, nonfloating seeds could be transferred through the river channel or into the floodplain by lateral turbulent exchanges. Therefore, a near surface sampling design such as ours could miss important seed transfers in high-energy rivers.

\section{Species traits and spatial variables}

Whether the floodplain functioned as a (net) seed source or sink for a certain species was influenced not only by phenology and flooding, but also by species traits and spatial variables. The number of seeds produced in the floodplain, in particular seed production at lower sites, was the main factor promoting (net) seed outflow. This is in line with the results of Boedeltje et al. (2003), who found for riparian species a positive correlation between seed production and the number of seeds trapped in a lowland stream. In addition, Peart (1989) found that the relative abundance of species in seed traps in open grassland patches is determined mainly by seed production. 
Thus, relatively high seed production is an important condition for seeds reaching the river. However, when we focus on those species that were captured in the river, seed production no longer appears as an important factor (see analysis $2 \mathrm{~b}$ in Table 2 ). The species groups compared in analysis $2 \mathrm{~b}$ concern seeds that have reached the river, either from outside the study area or from the Kappersbult. Thus, species with low seed production and therefore a lower variation in seed production in the floodplain were probably excluded. In this analysis, the spatial variables that appear important for net seed outflow are minimum soil elevation and minimum distance to the river. We suggest that the positive influence of low soil elevation on seed source behaviour might be related to the higher incidence of inundation at those sites. Furthermore, lower soil elevations occur at smaller distances to the river. Seeds of species growing at larger distances from the river (and thus higher elevation) might have a greater probability of capture by the standing vegetation in the floodplain before reaching the river. Lastly, species growing at low elevation close to the river are wetland species, which are generally adapted to hydrochory (high buoyancy) (see van den Broek et al. 2005). This might also explain why seeds originating from lower elevations are found in the downstream nets more often than seeds originating from higher elevation sites. The trend towards a lower minimum distance to the river for net source species stresses the above-suggested importance of proximity to the river for seed outflow, which is also indicated by the fact that a significantly greater number of species that grow at the riverbank than we had expected were net source species. Important species traits for net seed outflow were minimum plant height and buoyancy. The influence of plant height is probably due to the fact that wind acts as a primary dispersal vector for seed transport to the river, because plant height is known to be a major factor influencing wind dispersal distance (e.g. Soons et al. 2004; Muller-Landau et al. 2008). The significantly higher buoyancy for net source species than for net sink species is in line with the results of Boedeltje et al. (2003), who found that, next to seed production, buoyancy was the most important factor determining hydrochory for riparian species. Analogous to this, exclusive sink species tended to have lower buoyancy than species captured in both nets that were not found in the floodplain. This confirms the finding of Chang et al. (2008) that seeds with very low buoyancy are retained in larger numbers by the vegetation than seeds with higher buoyancy. On the other hand, high buoyancy will increase dispersal distance and thereby the probability that distant patches will be colonized (Pollux et al. 2009).

The seeds of exclusive sink species were found to be significantly heavier than those of species that occur in both nets and not in the floodplain, which indicates that heavier seeds are more likely to be deposited in the floodplain. This might be related to the fact that heavier seeds are often also relatively large. Schneider \& Sharitz (1988) indeed found that vegetation trapped larger water tupelo fruits more efficiently than it trapped smaller bald cypress seeds.

It should be noted that vegetative propagules were not taken into account in the current study. Boedeltje et al. (2003) found that $95.8 \%$ of the propagules captured in a lowland stream had a vegetative origin. However, $87.1 \%$ of the seeds of trapped (semi-)terrestrial species were generative diaspores (Boedeltje et al. 2003). Given that we were mainly interested in the source-sink dynamics of a floodplain, which implies a focus on (semi-)terrestrial species, we think that it is unlikely that the omission of vegetative propagules had an important effect on the results.

In summary, high seed production appears to be a major factor increasing the probability of seed outflow. However, a large number of seeds will not be available for the usually rare target species. Therefore, in addition to seed production, buoyancy, the distance of the growing location from, and its elevation in relation to, the river are expected to be the main factors determining species' ability to disperse via river water. This implies that it is unlikely that sources of floodplain species that are distant from the river, for instance, low-productive wet grasslands or litter meadows, will be successful in dispersing seed via river water. Further, such grasslands do not have high potential as a sink area because a lower frequency of inundation of these sites reduces the chance that target seeds will be deposited at locations that are suitable for their germination. Thus, once suitable abiotic conditions are restored, restoration of the biodiversity of floodplain communities that is facilitated by hydrochory can be successful for communities that are located in floodplains adjacent to and connected to the river, provided that the river water is not regulated.

\section{Acknowledgements}

The authors thank The Hunze and Aa Regional Water Board for providing data on river water level and discharge. Jos Verhoeven and two anonymous reviewers provided valuable comments that improved the manuscript.

\section{References}

Andersson, E., Nilsson, C. \& Johansson, M.E. 2000. Plant dispersal in boreal rivers and its relation to the diversity of riparian flora. Journal of Biogeography 27: 1095-1106. 
Baan, P.J.A. \& Klijn, F. 2004. Flood risk perception and implications for flood risk management in the Netherlands. International Journal of River Basin Management 2: 1-10.

Bakker, J.P., Brouwer, C., Van Den Hof, L. \& Jansen, A. 1987. Vegetational succession, management and hydrology in a Brookland (The Netherlands). Acta Botanica Neerlandica 36: 39-58.

Bischoff, A. 2002. Dispersal and establishment of floodplain grassland species as limiting factors in restoration. Biological Conservation 104: 25-33.

Bissels, S., Holzel, N., Donath, T.W. \& Otte, A. 2004. Evaluation of restoration success in alluvial grasslands under contrasting flooding regimes. Biological Conservation 118 : 641-650.

Boedeltje, G., Bakker, J.P., Bekker, R.M., Van Groenendael, J.M. \& Soesbergen, M. 2003. Plant dispersal in a lowland stream in relation to occurrence and three specific lifehistory traits of the species in the species pool. Journal of Ecology 91: 855-866.

Boedeltje, G., Bakker, J.P., Ten Brinke, A., Van Groenendael, J.M. \& Soesbergen, M. 2004. Dispersal phenology of hydrochorous plants in relation to discharge, seed release time and buoyancy of seeds: the flood pulse concept supported. Journal of Ecology 92: 786-796.

Cellot, B., Mouillot, F. \& Henry, C.P. 1998. Flood drift and propagule bank of aquatic macrophytes in a riverine wetland. Journal of Vegetation Science 9: 631-640.

Chang, E.R., Veeneklaas, R.M., Buitenwerf, R., Bakker, J.P. \& Bouma, T.J. 2008. To move or not to move: determinants of seed retention in a tidal marsh. Functional Ecology 22: $720-727$.

Ehrlen, J. \& Eriksson, O. 2000. Dispersal limitation and patch occupancy in forest herbs. Ecology 81: 1667-1674.

Ehrlen, J., Munzbergova, Z., Diekmann, M. \& Eriksson, O. 2006. Long-term assessment of seed limitation in plants: results from an 11-year experiment. Journal of Ecology 94: $1224-1232$.

Flynn, S., Turner, R.M. \& Stuppy, W.H. 2006. Seed information database. Royal Botanic Gardens, Kew. Available at: http:// data.kew.org/sid/sidsearch.html. Accessed 1 February 2008.

Goodson, J.M., Gurnell, A.M., Angold, P.G. \& Morrissey, I.P. 2003. Evidence for hydrochory and the deposition of viable seeds within winter flow-deposited sediments: the River Dove, Derbyshire, UK. River Research and Applications 19: 317-334.

Grootjans, A.P., Bakker, J.P., Jansen, A.J.M. \& Kemmers, R.H. 2002. Restoration of brook valley meadows in the Netherlands. Hydrobiologia 478: 149-170.

Gurnell, A., Goodson, J., Thompson, K., Clifford, N. \& Armitage, P. 2007. The riverbed: a dynamic store for plant propagules? Earth Surface Processes and Landforms 32: 1257-1272.

Gurnell, A., Thompson, K., Goodson, J. \& Moggridge, H. 2008. Propagule deposition along river margins: linking hydrology and ecology. Journal of Ecology 96: 553-565.
Gurnell, A.M., Boitsidis, A.J., Thompson, K. \& Clifford, N.J. 2006. Seed bank, seed dispersal and vegetation cover: colonization along a newly-created river channel. Journal of Vegetation Science 17: 665-674.

Hanski, I. 1999. Metapopulation ecology. Oxford University Press, Oxford, UK.

Jansson, R., Zinko, U., Merritt, D.M. \& Nilsson, C. 2005. Hydrochory increases riparian plant species richness: a comparison between a free-flowing and a regulated river. Journal of Ecology 93: 1094-1103.

Jansson, R., Nilsson, C. \& Malmqvist, B. 2007. Restoring freshwater ecosystems in riverine landscapes: the roles of connectivity and recovery processes. Freshwater Biology 52: 589-596.

Jensen, K., Trepel, M., Merritt, D. \& Rosenthal, G. 2006. Restoration ecology of river valleys. Basic and Applied Ecology 7: 383-387.

Junk, W.J., Bayley, P.B. \& Sparks, R.E. 1989. The floodplain concept in river systems. In: Dodge, D.P. (ed.) Proceedings of the International Large River Symposium (LARS). pp. 110-127. Department of Fisheries and Oceans, Ottawa, Honey Harbour, ON, CA.

Kleyer, M., Bekker, R.M., Knevel, I.C., Bakker, J.P., Thompson, K., Sonnenschein, M., Poschlod, P., van Groenendael, J.M., Klimés, L., Klimesova, J., Klotz, S., Rusch, G.M., Hermy, M., Adriaens, D., Boedeltje, G., Bossuyt, B., Dannemann, A., Endels, P., Götzenberger, L., Hodgson, J.G., Jackel, AK., Kühn, I., Kunzmann, D., Ozinga, W.A., Römermann, C., Stadler, M., Schlegelmilch, J., Steendam, H.J., Tackenberg, O., Wilmann, B., Cornelissen, J.H.C., Eriksson, O., Garnier, E. \& Peco, B. 2008. The LEDA Traitbase: a database of life-history traits of the Northwest European flora. Journal of Ecology 96: 1266-1274.

Klimkowska, A., van Diggelen, R., den Held, S., Brienen, R., Verbeek, S. \& Vegelin, K. 2009. Seed production in fens and fen meadows along a disturbance gradient. Applied Vegetation Science 12: 304-315.

Merritt, D.M. \& Wohl, E.E. 2006. Plant dispersal along rivers fragmented by dams. River Research and Applications 22: 1-26.

Middleton, B.A. 1999. Wetland restoration. Flood pulsing and disturbance dynamics. John Wiley and Sons, New York, NY, US.

Moggridge, H.L. \& Gurnell, A.M. 2010. Hydrological controls on the transport and deposition of plant propagules within riparian zones. River Research and Applications 26: 512-527.

Moggridge, H.L., Gurnell, A.M. \& Mountford, J.O. 2009. Propagule input, transport and deposition in riparian environments: the importance of connectivity for diversity. Journal of Vegetation Science 20: 465-474.

Muller-Landau, H.C., Wright, S.J., Calderón, O., Condit, R. \& Hubbell, S.P. 2008. Interspecific variation in primary seed dispersal in a tropical forest. Journal of Ecology 96: 653-667.

Nienhuis, P.H. \& Leuven, R. 2001. River restoration and flood protection: controversy or synergism? Hydrobiologia 444: 85-99. 
Nienhuis, P.H., Buijse, A.D., Leuven, R., Smits, A.J.M., de Nooij, R.J.W. \& Samborska, E.M. 2002. Ecological rehabilitation of the lowland basin of the River Rhine (NW Europe). Hydrobiologia 478: 53-72.

Nilsson, C., Gardfjell, M. \& Grelsson, G. 1991. Importance of hydrochory in structuring plant communities along rivers. Canadian Journal of Botany 69: 2631-2633.

Ozinga, W.A., Schaminee, J.H.J., Bekker, R.M., Bonn, S., Poschlod, P., Tackenberg, O., Bakker, J. \& van Groenendael, J.M. 2005. Predictability of plant species composition from environmental conditions is constrained by dispersal limitation. Oikos 108: 555-561.

Peart, D.R. 1989. Species interactions in a successional grassland.1. Seed rain and seedling recruitment. Journal of Ecology 77: 236-251.

Pollux, B.J.A., Verbruggen, E., van Groenendael, J.M. \& Ouborg, N.J. 2009. Intraspecific variation of seed floating ability in Sparaganium emersum suggests a bimodal dispersal strategy. Aquatic Botany 90: 199-203.

Rosenthal, G. 2006. Restoration of wet grasslands - effects of seed dispersal, persistence and abundance on plant species recruitment. Basic and Applied Ecology 7: 409-421.

Schneider, R.L. \& Sharitz, R.R. 1988. Hydrochory and regeneration in a Bald Cypress Water Tupelo swamp forest. Ecology 69: 1055-1063.

Soomers, H., Winkel, D.N., Du, Y. \& Wassen, M.J. 2010. The dispersal and deposition of hydrochorous plant seeds in drainage ditches. Freshwater Biology 55: 2032-2046.

Soons, M.B., Heil, G.W., Nathan, R. \& Katul, G.G. 2004. Determinants of long-distance seed dispersal by wind in grasslands. Ecology 85: 3056-3068.

Tockner, K., Malard, F. \& Ward, J.V. 2000. An extension of the flood pulse concept. Hydrological Processes 14: 2861-2883.

van den Broek, T., van Diggelen, R. \& Bobbink, R. 2005. Variation in seed buoyancy of species in wetland ecosystems with different flooding dynamics. Journal of Vegetation Science 16: 579-586.

van der Meijden, R. 2005. Heukels' Flora van Nederland. 23. Wolters-Noordhoff bv, Gröningen, NL.

van Heerd, R.M., Kuijlaars, E.A.C., Teeuw, M.P. \& van't Zand, R.J. 2000. Productspecificatie AHN 2000. MDTGM2000, 13. Rijkswaterstaat, Delft.

Vogt, K., Rasran, L. \& Jensen, K. 2004. Water-borne seed transport and seed deposition during flooding in a small river-valley in Northern Germany. Flora: Morphologie, Geobotanik, Oekophysiologie 199: 377-388.

Vogt, K., Rasran, L. \& Jensen, K. 2006. Seed deposition in drift lines during an extreme flooding event - evidence for hydrochorous dispersal? Basic and Applied Ecology 7: 422-432.

Vogt, K., Rasran, L. \& Jensen, K. 2007. Seed deposition in drift lines: opportunity or hazard for species establishment? Aquatic Botany 86: 385-392.

\section{Supporting Information}

Additional Supporting Information may be found in the online version of this article:

Table S1. Plant species for which (I) seeds were captured in the River Drentsche Aa and/or (II) occur in the Kappersbult floodplain (last column). The second and third columns indicate number of seeds caught downstream and upstream, respectively, computed to annual figures.

Please note: Wiley-Blackwell is not responsible for the content or functionality of any supporting materials supplied by the authors. Any queries (other than missing material) should be directed to the corresponding author for the article. 